\title{
Peran Komunikasi Verbal Dalam Penggunaan Media Gambar Untuk Meningkatkan Kemampuan Berbahasa Mandarin Bagi Anak Taman Kanak-kanak
}

\author{
Maisyah Putri \\ Yayasan Sekolah Cinta Budaya \\ e-mail: maisyahp@gmail.com
}

\begin{abstract}
The media image serves to attract attention to more easily understood student learning. delivered by teachersThus verbal communication is still the main communication in learning in the media uses only verbal communication the extent to which it is used and how much affect does that have on increased capacity in. mandarinThe study aimed to identify the role of verbal communication in the use of media images to improve the ability to speak mandarin.The methodology was. This is a descriptive qualitative research methodology. The result showed that media uses pictures is one of the means by which to improve their performance is very effective schooling particularly mandrin language lessons. It was in this picture are serves to attract attention to more easily understood student learning mandarin delivered by teachers .
\end{abstract}

Key word: Verbal communication, Media pictures, chinese

\begin{abstract}
Abstrak
Media gambar berfungsi untuk menarik perhatian murid agar lebih mudah memahami pembelajaran yang disampaikan oleh guru. Dengan demikian komunikasi verbal masih merupakan komunikasi yang utama dalam pembelajaran disamping penggunaan media gambar hanya saja sejauh mana komunikasi verbal itu digunakan dan seberapa besar pengaruhnya terhadap peningkatan kemampuan berbahasa Mandarin. Penelitian ini bertujuan untuk mengetahui peran komunikasi verbal dalam penggunaan media gambar untuk meningkatkan kemampuan berbahasa Mandarin. Metode penelitian ini bersifat deskriptif kualitatif. Hasil penelitian menunjukkan bahwa penggunaan media gambar merupakan salah satu sarana yang sangat efektif untuk meningkatkan prestasi belajar khususnya pelajaran bahasa Mandrin. Hal itu terlihat pada gambar yng berfungsi untuk menarik perhatian murid agar lebih mudah memahami pembelajaran bahasa Mandarin yang disampaikan oleh guru.
\end{abstract}

Kata kunci: Komunikasi Verbal, Media Gambar, Bahasa Mandarin 
Latar Belakang Masalah

Memasuki era globalisasi seperti sekarang ini peranan bahasa Mandarin sangat penting, apalagi sekarang menjadi bahasa Internasional kedua setelah bahasa Inggris. Penggunaan bahasa Mandarin sangat dibutuhkan guna memperlancar hubungan bisnis, studi, perdagangan, dan pariwisata. Pentingnya mempelajari bahasa asing dijadikan sebagai suatu persiapan demi meningkatkan kompetensi saat memasuki dunia kerja. Kesadaran ini membuat banyak orang Indonesia tertarik mempelajari bahasa Mandarin. Sudah banyak lembaga formal maupun non formal yang telah mengadakan pelajaran bahasa Mandarin. Seperti di lembaga sekolah negeri maupun swasta dan di lembaga kursus yang ada di daerahdaerah Indonesia.

Seiring dengan pesatnya perkembangan bahasa Mandarin di Indonesia, maka pemerintah khususnya Direktorat Jendral Pendidikan Dasar dan Menengah melakukan kerja sama dengan The China National for Teaching Chinese as a Foreign Language melalui kedutaan Besar RRC untuk Indonesia dalam rangka peningkatan kompetensi guru-guru bahasa Mandarin di sekolah-sekolah Indonesia. Akan tetapi ada beberapa permasalahan yang dihadapi dalam pelaksanaan pembinaan dan pengembangan pendidikan bahasa Mandarin di Indonesia antara lain masih terbatasnya jumlah dan kualitas tenaga guru/pendidik/ instruktur bahasa Mandarin yang memiliki kualifikasi dan kompetensi yang sesuai dengan kebutuhan. Untuk mengetahui permasalahan ini, maka pemerintah Indonesia melakukan kerjasama dengan pemerintah China dalam hal peningkatan mutu tenaga pendidik bahasa Mandarin di Indonesia.

Belajar bahasa Mandarin otak harus berhubungan dengan dua jurusan yang berbeda sekaligus, yaitu: bunyi dan arti, itulah sebabanya anak yang sejak kecil belajar bahasa Mandarin Intelligent Question (IQ) nya naik antara 15\%$20 \%$. Dengan itu, diharapkan bahasa Mandarin dapat dipelajari sejak kecil karena selain anak-anak lebih cepat dalam menyerap pelajaran, bahasa Mandarin merupakan bahasa yang 
susah dan memiliki banyak kosakata. (http:syilvitanaga.wordpress.com/20 $\underline{08 / 02 / 17 / p e n t i n g n y a-b a h a s a-}$

Mandarin.di-era-globalisasi).

Bahasa Mandarin merupakan salah satu mata pelajaran di Sekolah Cinta Budaya. Untuk itu, peneliti berusaha menggunakan metode dan media yang tepat untuk lebih menarik perhatian murid saat proses belajar mengajar dan membuat murid merasa senang dalam belajar bahasa Mandarin. Sesuai dengan karakteristik peserta didik anak TK yang masih senang bermain, senang bergerak, menemukan hal-hal baru dalam kehidupan, maka murid ingin melihat secara langsung gambaran yang mereka dapatkan saat menerima kosakata baru dalam pelajaran bahasa Mandarin. Oleh karena itu, media gambar merupakan media yang sangat berperan penting dalam proses pembelajaran.

Media gambar berfungsi untuk menarik perhatian murid agar lebih mudah memahami pembelajaran yang disampaikan oleh guru. Selain itu manfaat yang dapat diperoleh dari media gambar yaitu, proses pembelajaran menjadi lebih mudah diserap, kualitas belajar murid dapat meningkat, dan peran guru dapat berubah ke arah yang lebih menarik dan interaktif, maka dari itu media gambar sering digunakan bahasa asing maupun bahasa Indonesia.

Media gambar adalah segala sesuatu yang di wujudkan secara visual ke dalam bentuk dua dimensi sebagai curahan atau pun pikiran yang bentuknya bermacam-macam seperti lukisan, poter, slide, fil, strip, dan opaque projector Hamalik:2010). Sementara itu Bretz (2007) menjelaskan media gambar merupakan peniruan dari bendabenda dan pemandangan dalam hal bentuk, rupa, serta ukurannya relative terhadap lingkungan

Karakteristik dari media gambar ini menurut Riyanto (2007) terdiri atas: 1) Harus autentik, artinya dapat menggambarkan objek/pariwisata seperti jika siswa melihat langsung. 2) Sederhana, komposisinya cukup jelas menunjukkan bagian-bagian pokok dalam gambar tersebut. 3) Ukuran gambar propesional, sehingga siswa adalah membayangkan ukuran sesungguhnya benda/objek digambar. 4) Memudahkan antara 
keindahan dengan kesesuaiannya untuk mencapai tujuan pembelajaran.

5) Gambar harus message, tidak seperti gambar yang bagus merupakan media yang bagus. Sebagaimana media yang baik, gambar hendaklah bagus dari sudut seni dan sesuai dengan tujuan pembelajaran yang ingin dicapai.

Meskipun media gambar berperan penting dalam pembelajaran terutama bahasa asing maupun bahasa Indonesia, maka para guru selalu menjelaskan kembali gambar yang mereka perlihatkan agar murid dapat mengingatnya kembali. Dengan demikian komunikasi verbal masih merupakan komunikasi yang utama dalam pembelajaran disamping penggunaan media gambar.

Komunikasi verbal adalah komunikasi yang menggunakan simbol-simbol verbal, baik secara lisan maupun tertulis. Simbol atau pesan verbal adalah semua jenis simbol yang menggunakan satu kata atau lebih (Mulyana:2008:104). Hampir semua rangsangan bicara yang kita sadari termasuk ke dalam kategori pesan verbal sengaja, yaitu usaha-usaha yang dilakukan secara sadar untuk berhubungan dengan orang lain secara verbal.

Sekolah Cinta Budaya hal tersebut juga dilakukan para guru hanya saja sejauh mana komunikasi verbal itu digunakan dan seberapa besar pengaruhnya terhadap peningkatan kemampuan berbahasa Mandarin pada murid.

\section{Metode Penelitian}

Jenis penelitian yang digunakan adalah penelitian kualitatif. Penelitian kualitatif adalah penelitian yang bermaksud untuk memahami fenomena tentang apa yang dialami oleh subjek penelitian misalnya perilaku, persepsi, motivasi, tindakan dan lain lain secara holistic, dan dengan cara deskripsi dalam bentuk kata-kata dan bahasa, pada waktu konteks khusus alamiah dan dengan memanfaatkan berbagai metode alamiah (Moleong:2017).

Penelitian akan menjelaskan atau mendeskipsikan mengenai peran komunikasi verbal dalam penggunan media gambar untuk meningkatkan kemampuan berbahasa Mandarin melalui data yang diperoleh. 
Hasil Penelitian dan Pembahasan

\begin{tabular}{lll}
\multicolumn{2}{c}{ Penelitian tentang } & peran \\
komunikasi & verbal & dalam \\
penggunaan media & gambar & untuk \\
meningkatkan & \multicolumn{2}{c}{ kemampuan }
\end{tabular}

berbahasa Mandarin tergolong cukup baik. Hal ini terlihat dari hasil wawancara dan observasi yang peneliti lakukan, dimana peneliti menyaksikan langsung komunikasi guru dengan murid sangat komunikatif, ini terlihat saat proses belajar mengajar murid bertanya kepada guru tentang pelajaran yang belum ia mengerti dan guru akan mengulang kembali pelajaran yang telah disampaikannya. Semua gambar tertera disampingnya tulisan Mandarin yang menyebutkan nama gambar tersebut tidak terdapat tulisan bahasa Indonesia dalam gambar.

Guru melakukan atau melaksanakan pembelajaran bahasa Mandarin kepada murid menggunakan media gambar. Guru menyebutkan nama setiap gambargambar yang ditampilkan dalam bahasa Mandarin. Adapun gambar yang ditampilkan adalah tentang kehidupan didalam lautan, dan wajah manusia. Guru yang menjelaskan situasi atau cerita yang ditampilkannya ada pada gambar. Setelah guru menyebutkan nama gambar-gambar tersebut guru menyuruh murid untuk mengulangnya bersama-sama kemudian menyuruh satu persatu untuk mengulangnya kembali.

Setelah seminggu berlalu pengajaran bahasa Mandarin dengan menampilkan gambar-gambar guru menyuruh kembali satu persatu murid untuk menyebut tanpa dipandu oleh guru. Sebagian masih ada murid yang belum mampu menyebutkan kalimat bahasa Mandarin guru akan mengulang-ulang kembali apa yang diajarkan untuk diikuti oleh murid. Gambar-gambar tersebut berasal dari buku panduan yang memang telah disediakan oleh sekolah.

Penggunaan gambar ini bertujuan agar murid lebih mudah mengerti pelajaran bahasa Mandarin sebagimana yang telah disampaikan oleh informan kunci. Pengulangan kata-kata oleh guru dilakukan sampai setiap murid hafal apa yang telah ditampilkan dalam bahasa Mandarin. Gambar-gambar yang dipilih adalah gambar-gambar yang menarik perhatian murid seperti pembelajaran 
bahasa Mandarin dengan tema

kehidupan didalam lautan berupa gambar ikan hiu, kura-kura, rumput laut, dan gurita.

Murid yang mampu menyebutkan kembali ke dalam bahasa Mandarin guru akan memberinya point berupa stiker dan permen sebagai hadiah. Kadang kala guru memberi hukuman yang tidak bisa menjelaskan gambar-gambar tersebut dalam bahasa Mandarin dan menerjemahkannya ke dalam bahasa Indonesia ini dilakukan oleh guru agar murid menaruh perhatian penuh kepada penjelasan guru ketika guru menjelaskan gambar-gambar yang ditampilakan guru juga melakukan tanyajawab yang pertanyaannya adalah seputar gambar. Murid yang dapat mengucapkan dengan baik akan diberikan point berupa stiker dan permen sebagai hadiah.

\section{Penutup}

Penggunaan media gambar sebagai alat pembelajaran sangat berperan penting untuk meningkatkan kemampuan murid dalam berkomunikasi menggunakan bahasa Mandarin. Penggunaan media gambar ini hanya efektif diikuti dengan penjelasan secara verbal oleh guru. Peran komunikasi verbal dalam penggunaan media gambar sangat berperan besar untuk meningkatkan kemampuan berbahasa Mandarin.

Media gambar dalam proses pembelajaran khususnya pelajaran bahasa Mandarin akan memudahkan guru saat menyampaikan materi pelajaran bahasa Mandarin kepada murid. Namun gambar tersebut harus dijelaskan secara verbal oleh guru

Sekolah Cinta Budaya menjadikan bahasa Mandarin sebagai bahasa yang wajib dipelajari oleh setiap murid. Oleh karena itu, setiap murid setelah mempelajarari bahasa Mandarin harus mampu menggunakannya sebagai alat komunikasi. Keberhasilan komunikasi verbal dalam menyampaikan gambar agar anak memahami materi pembelajaran sangat dipengaruhi oleh kemampuan berbahasa Mandarin dalam menggunakan dan mengucapkan kata-kata. 


\section{Daftar Pustaka}

Bertz, Rudy, 2007. A Toxonomi of Communication Media, Education Technology Publication, Englewood, Chilffs N.J

Hamalik, Oemar. 2010. Metode Belajar dan Kesulitankesulitan Belajar. Rosda Karya: Bandung.

Moleong L. 2017. Metode Penelitian Kualitatif Edisi Revisi. PT Remaja Rosdakarya: Bandung

Mulyana Deddy. 2008. Human Comunication Prinsip-prinsip Dasar. Remaja Rosdakarya: Bandung.

Riyanto. 2007. Media Pengajaran.

Dekdikbud: Jakarta. 